\title{
O Maciço do Morro da Cruz (MMC) em Florianópolis (SC): de não território a território do PAC
}

\author{
The "Maciço do Morro da Cruz" in Florianópolis (SC): from non \\ territory to a PAC territory
}

http://dx.doi.org/10.5007/2178-4582.2015v49n1p165

Elaine Dorighello Tomás

Luiz Fernando Scheibe

Universidade Federal Santa Catarina, Florianópolis/SC, Brasil

\begin{abstract}
Considerado inicialmente como um "Não Território", o Maciço do Morro da Cruz (MMC) será ao longo da urbanização de Florianópolis apropriado e reterritorializado até se caracterizar, em 2012, como "Território do PAC-Florianópolis". Sua população, apesar de viver em uma área central, é considerada periférica. Tratada como uma "cidade irregular", de assentamentos precários, não escapa a problemas urbanos - sociais e ambientais. Composta por cerca de 18 comunidades, por muito tempo sofreu pela ausência de investimentos públicos e de reconhecimento de seus direitos cidadãos. Este estudo consiste na análise do histórico das diversas territorialidades constituídas no MMC, a partir de sua ocupação como área periférica, passando pela deliberada construção conceitual de um Território (do Fórum) do MMC, até as versões conflitantes de um Território das Zeis e um Território do PAC-Florianópolis, com o objetivo de apurar se essas ações têm condições de contribuir para a inclusão social das comunidades envolvidas.
\end{abstract}

Palavras-chave: Território - Maciço do Morro da Cruz - PAC- Florianópolis - ZEIS Movimentos Sociais.
Initially considered as a "Non Territory", the Maciço do Morro da Cruz (MMC) has been modified several times during the urbanization of Florianópolis, until the moment in 2012 when it was characterized as the "PACFlorianopolis Territory". Despite living in a central area of the city, its population is considered peripheral. Called a "irregular city, it doesn't escape many urban, social and environmental problems. It's composed of about 18 communities that suffered for a long time the lack of public investment and recognition of their civic rights. The study provides an historical analysis of the different territorialities established over time in the MMC, both from its initial occupation as a peripheral area, passing through deliberate conceptual construction of the "MCC (Forum) Territory", to the conflicting versions of a "Zeiss Territory" and the "PACFlorianopolis Territory", to verify if these actions constitute effective contibutions to the social inclusion of the affected communities.

Keywords: Territory - Maciço do Morro da Cruz - Growth Accelaration PlanFlorianopolis - ZEIS - Social Movments.

\section{Introdução}

O Maciço do Morro da Cruz (MMC) encontra-se na porção central de Florianópolis e pode-se ali observar a presença da chamada "cidade irregular" , formada por pelo menos dezoito comunidades que reuniriam uma população aproximada de 26.000 pessoas (PMF, 2006a). Esta população, apesar de viver 
em uma área central do atual aglomerado urbano, é considerada periférica à cidade. É um conjunto de comunidades que fala desde uma Florianópolis invisível, que desafia as políticas públicas da administração local e que, com certeza, demanda melhor reconhecimento.

A fim de enfrentar e superar as dificuldades comuns a estas comunidades, onze associações de moradores se reuniram formando, a partir de 1999, o Fórum das Comunidades do Maciço do Morro da Cruz - FMMC. Como reivindicações comuns apresentavam as seguintes demandas: regularização fundiária, implementação de infraestrutura e garantia dos direitos sociais. Com estes objetivos em pauta, o FMMC elaborou um Plano de Ações, visando atingir as demandas prioritárias que haviam sido assinaladas pelas diferentes comissões: Comissão de Educação, Esporte e Lazer; de Meio Ambiente; de Segurança, Trabalho e Renda (SCHEIBE et al, 2007).

Neste contexto de discussões do Fórum do Maciço do Morro da Cruz, consolidou-se o apoio das principais lideranças das comunidades a duas propostas, oficializadas pela Secretaria Municipal de Habitação e Saneamento Ambiental (SMHSA) e pelo Instituto de Planejamento Urbano de Florianópolis (IPUF), que se transformaram em leis, pela Câmara Municipal e Prefeitura: a implementação de Zonas Especiais de Interesse Social - ZEIS - nas áreas já ocupadas - lei complementar No 207 de 28 de dezembro de 2005, e a criação e implementação de um parque municipal abrangendo toda a área remanescente, não ocupada - lei N N$^{\mathrm{o}} 6893$ de 08 de dezembro de 2005 (CÂMARA MUNICIPAL DE FLORIANÓPOLIS, 2005).

Aaprovaçãodaleicomplementar207/2005 representouumaimportanteconquista do movimento social do Fórum do MMC, pois permitiu a classificação de boapartedessas 18 comunidades comoZonasEspeciaisdeInteresseSocial(ZEIS) , instrumento previsto no Estatuto da Cidade, prevendo ainda inúmeras benfeitorias e a possibilidade da regularização fundiária das áreas ocupadas.

A partir daí, contudo, novos agentes assumiram os papéis preponderantes no cenário do Maciço: os técnicos da Secretaria Municipal de Habitação e Saneamento Ambiental (SMHSA) da Prefeitura Municipal de Florianópolis, os da Caixa Econômica Federal, os das diversas empresas de consultoria, contratadas para elaboração de estudos e projetos de Desenvolvimento Institucional (DIs), visando captar investimentos para obras estruturais no Maciço.

Em 2008, novas perspectivas se apresentaram para o MMC, com o anúncio do repasse de $\mathrm{R} \$ 54,6$ milhões para obras do Programa do Maciço do Morro da Cruz/PAC - Florianópolis. Estes recursos, 46\% provenientes do governo federal, $27 \%$ do governo estadual e $27 \%$ da prefeitura, foram destinados principalmente a obras de infraestrutura e à implantação do Parque Natural do MMC. 


\section{Metodologia e técnicas de pesquisa}

O presente artigo se inscreve no esforço de análise qualitativa e quantitativa dos empreendimentos promovidos pelo PAC no MMC. O Ministério das Cidades tem demonstrado especial interesse em apurar impactos que as ações do PAC têm produzido nas porções mais empobrecidas das cidades ao patrocinar diversas pesquisas para avaliar o impacto pós-ocupação destas obras . O principal objetivo que se busca com aquela pesquisa é apurar se as obras realizadas têm condições de contribuir efetivamente para a inclusão social das comunidades envolvidas.

Para a coleta de dados sobre a área de estudo, foram utilizadas entre outras modalidades: entrevistas (estruturadas ou não), observação participante, questionários, levantamentos, mapeamentos e análises.

Entre os procedimentos metodológicos utilizados tem-se:

- Utilização de imagens (aéreas e digitais) defasadas no tempo para avaliar a extensão das modificações ocorridas;

- Análise e atualização dos dados obtidos nas pesquisas das empresas consultoras contratadas pela Prefeitura Municipal de Florianópolis (PMF);

- Questionários, entrevistas e indicadores destinados à análise da situação atual de inclusão/exclusão dos moradores das áreas definidas previamente como ZEIS.

\section{As reterritorializações do Maciço do Morro Da Cruz - MMC}

Considerado inicialmente como um "Não Território" ou “Território do Abandono e do Degredo", o Morro da Cruz será, durante a crescente urbanização de Florianópolis, sucessivamente apropriado e reterritorializado até vir a ser caracterizado como o Território (do Fórum) do Maciço do Morro da Cruz, ao qual se superimpõe, hoje, o Território do PAC-Florianópolis.

Segundo Scheibe (2002), pela localização do MMC na porção central da ilha (Figura 1) as áreas ambientalmente frágeis sofreram forte pressão no decurso da ocupação, especialmente por migrantes do interior do estado, apesar das restrições de caráter legal (ambientais e urbanísticas). Encostas íngremes e áreas de nascentes onde a vegetação encontrava-se ainda preservada ou em estado de regeneração (sucessão natural ecológica) foram cada vez mais ocupadas, tanto por loteamentos "regulares" como pela população excluída do 
processo da constituição da cidade legal. Algumas áreas ocupadas da encosta, anteriormente recobertas pela vegetação, expõem agora campos de blocos de matacões que podem vir a se desestabilizar com a gradativa retirada dos materiais mais finos pelos processos erosivos.

Figura 1. Localização geográfica da área de estudo

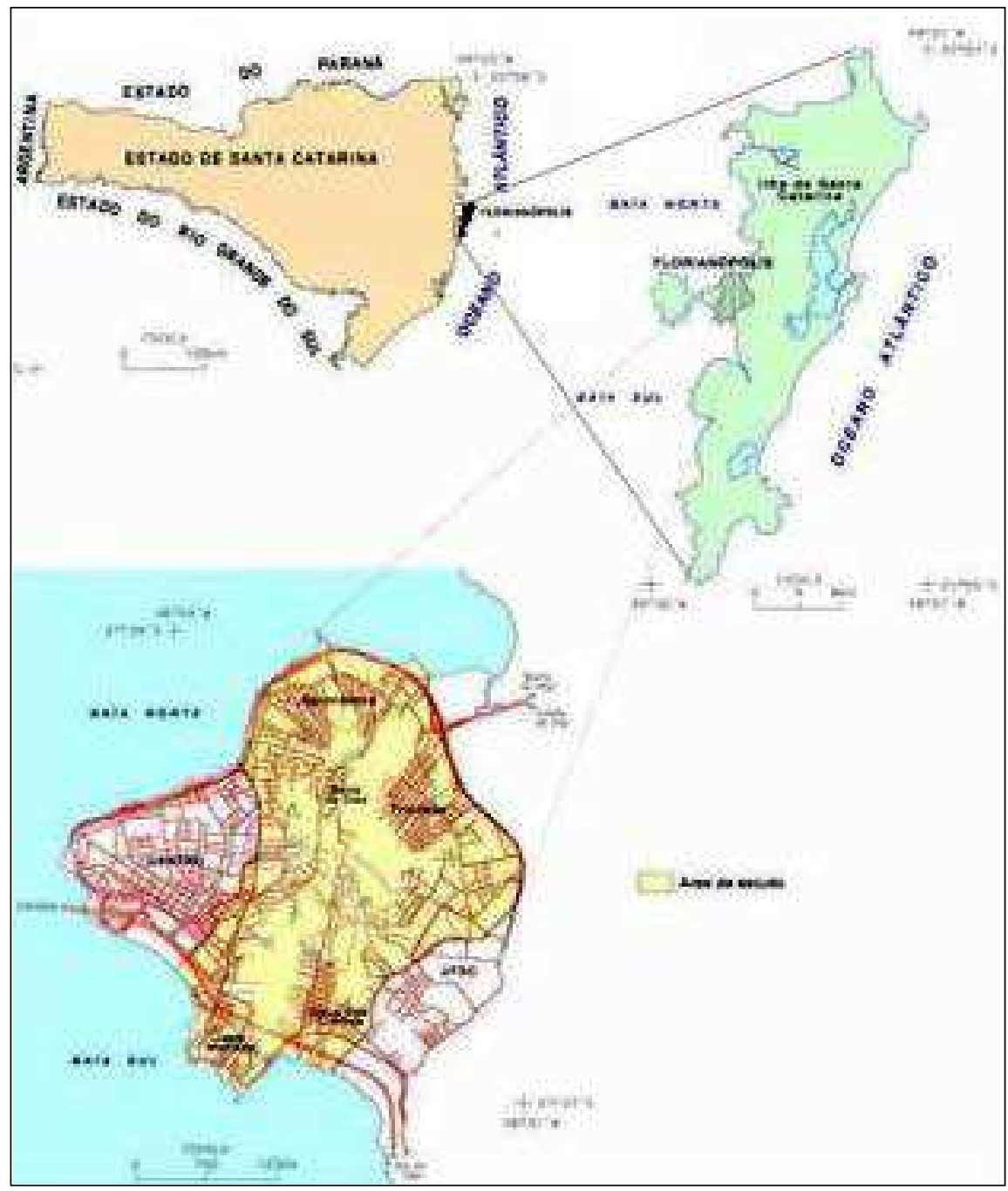

Fonte: Levantamento aerofotogramétrico do aglomerado urbano de Florianópolis. Escala 1:10000, PMF, 1979. Ortofotocarta do município de Florianópolis, Escala 1:5000, IPUF/ Aeroconsult, 2002. Produzido no Laboratório de Geoprocessamento/Departamento de Geociências/CFH/UFSC. 
Diante deste contexto de ocupação de áreas ambientalmente frágeis, os problemas da população não podem ser reduzidos apenas aos aspectos físicos dessas áreas, pois o meio ambiente deve ser considerado como algo não passível de redução ao meio natural, mas que engloba também o ambiente socialmente construído:

\begin{abstract}
Problemas como a falta de saneamento básico nos espaços urbanos pobres e segregados são, indiscutivelmente, problemas urbanos primários e, ao mesmo tempo, problemas ambientais. Aliás, em metrópoles do Terceiro Mundo, esse tipo de problema ambiental, diretamente vinculado a esses subprodutos da urbanização capitalista periférica, que são a pobreza e a segregação em larga escala, é um dos mais importantes (SOUZA, 2005, p. 116-7).
\end{abstract}

Pode-se dizer assim, ainda de acordo com Souza (2005), que os problemas ambientais são todos aqueles que, por uma razão ou outra, interferem negativamente na qualidade de vida dos indivíduos no contexto da sua interação com o espaço, seja ele natural ou social.

Tomás (2012) considera que o território do MMC passou por uma ação desmobilizadora na organização comunitária, enfraquecendo o movimento social, anteriormente sustentado nas reivindicações por atendimento às necessidades básicas de infraestrutura, os quais segundo Souza (2005) podem ser considerados problemas urbanos primários e ao mesmo tempo problemas ambientais.

Durante muitos anos, as comunidades do Morro da Cruz tiveram sua existência negada ou ignorada pelos poderes públicos locais, como se constituíssem uma porção invisível desta mesma cidade. Serviam, por certo, para abrigar de forma discreta os membros preferencialmente excluídos do meio urbano, embora importantes como fornecedores de mão de obra barata, como as lavadeiras, as empregadas domésticas, os carregadores do Mercado Público e os serventes da construção civil.

Para Souza (2005), o território se manifesta na sociedade em constante movimento, que disputa o espaço não só como recurso, mas também como suporte temporal. Esta definição - território enquanto espaço definido e delimitado por e a partir de relações de poder - possibilita o entendimento deste enquanto uma área de disputa e de domínio de um determinado grupo sobre outro.

Considerando os diversos significados e relações ensejados pelos atores envolvidos, internos ou externos ao MMC, pode-se pensar em distintas terri- 
torialidades para o conjunto das comunidades, ao longo dos períodos históricos de sua constituição.

A ocupação inicial do Morro da Cruz ocorreu a partir da metade do século XVIII, quando pessoas vindas de muitos lugares vão habitar, esparsamente, as suas encostas. No entanto, aqueles que procuravam esta região são os que, de uma maneira ou outra, estavam à margem do contexto social da época. Este primeiro período se estendeu praticamente por quase todo século XIX e foi um período de lenta ocupação, quando muitos procuravam as imediações do caminho que atravessava o morro como local de refúgio.

Um segundo período - este de ocupação mais expressiva - ocorre a partir da década de 1910, em decorrência das mudanças sanitaristas que expulsaram os pobres do perímetro urbano. Dá-se quando a limpeza higienista e o embelezamento da cidade são cultivados, enquanto ideário moderno a ser perseguido. Aos pobres estavam destinadas as áreas alagadiças, os cortiços ou as encostas dos morros. Temos, então, a consolidação de comunidades como o Mont Serrat, por exemplo.

Um terceiro período, este mais breve, está relacionado ao final da construção da ponte Hercílio Luz, nos anos 1920. O Morro do Mocotó, Morro do Bode e Morro da Queimada, por exemplo, são comunidades que têm sua história mesclada com a história da construção da ponte. São comunidades que fazem parte da história da própria cidade, embora ainda da história dos invisíveis.

O próximo período de ocupação, ou construção de uma nova territorialidade, inicia nos anos 40 e 50 do século passado, quando as curvas de urbanização passam a crescer expressivamente em relação a uma quase estagnação da população rural, que só passaria a decrescer acentuadamente no Brasil, em termos absolutos, a partir dos meados da década de 1960 (THÉRY; MELLO, 2005), trazendo vários fluxos de migrantes para a capital. Essa população buscava trabalho principalmente na construção civil, durante o período de expansão da atividade em Florianópolis, principalmente ao longo da década de 1960. Grande parte da população migrante chegava à capital sem opção de terra barata para morar, passando a procurar os morros. Um segundo fluxo migratório importante ocorreu um pouco mais tarde, já nos anos 1980. O Morro da Cruz seria um dos escassos lugares onde uma família pobre poderia encontrar uma área, ocupar um terreno, comprar uma "posse" ou alugar uma casa, em uma área localizada próxima ao centro de Florianópolis.

Uma quinta territorialidade, embora ainda dispersa, configura-se pelos laços da solidariedade e da cooperação tão característicos entre os pobres. São tempos e lugares recordados hoje por antigos moradores com certo romantismo nostálgico, mas cujas características preparam o caminho para o estabe- 
lecimento de um movimento social unificado. Para a unificação das diversas comunidades num único movimento social, assume caráter essencial a compreensão de que a própria expansão de Florianópolis para leste, ao contornar de forma excludente o conjunto dessas comunidades, acaba por conferir-lhes uma identidade comum, adequadamente caracterizada pelos próprios moradores como um território: o Território do Maciço (Central) do Morro da Cruz.

Através da atuação do Fórum do Maciço do Morro da Cruz, podemos falar na consolidação de um verdadeiro "Território (do Fórum) do Maciço", não apenas do ponto de vista dos moradores como na percepção dos órgãos públicos e da própria imprensa, que a ele ainda se refere enquanto tal. As ZEIS, com a respectiva regularização fundiária específica, representariam a garantia de inserção do Território do Maciço do Morro da Cruz à cidade formal, e também a possibilidade dos atuais moradores adquirirem, finalmente, sua plena cidadania.

O território das ZEIS, defendido pelo movimento social do Fórum do $\mathrm{MMC}$, teria como ações características a regularização fundiária e a implementação de equipamentos comunitários como creches, equipamentos de lazer, posto de saúde, polícia comunitária. Seria o 'Território das ZEIS' - percebido enquanto lugar de disputa de diferentes grupos. É fugaz pelo fato desta territorialidade, que sequer chegou a ser plenamente constituída, haver sido rapidamente obliterada pelas consequências das obras trazidas pelo Projeto do PAC-Florianópolis para o Maciço do Morro da Cruz.

Os vultosos recursos liberados pelo Governo Federal ao PAC-Florianópolis em março de 2008 serão, então, aplicados principalmente em obras gerais de infraestrutura, também necessárias, como a abertura e pavimentação de ruas e instalação de redes de abastecimento de água, energia elétrica e de esgotos, e ocorreram com o acompanhamento de um Núcleo Gestor do qual participaram representantes de cada comunidade específica, porém sem qualquer relação institucional com o Fórum do Maciço do Morro da Cruz. Podemos, então, falar da constituição de uma nova territorialidade, a do Território do PAC-Florianópolis.

\section{O Programa de Aceleração Do Crescimento (PAC) no Maciço do Morro da Cruz}

O Programa de Aceleração do Crescimento - PAC - no Maciço do Morro da Cruz começou a ser gestado em 2005, quando se iniciou o levantamento, pela PMF, das necessidades da população, devido às pressões dos Conselhos Comunitários liderados pelo Fórum do MMC. Ao longo de 2005, as visitas de autoridades e técnicos municipais ao Maciço se intensificaram e um grupo executivo de trabalho foi formado. Em reuniões ampliadas com a comunida- 
TOMÁS, Elaine Dorighello; SCHEIBE, Luiz Fernando. O Maciço do Morro da Cruz (MMC) em...

de, foi detectada a enorme fragilidade social e ambiental desta área e, também, uma grande demanda pela regularização fundiária.

Figura 2. Mapa com as delimitações das comunidades no MMC

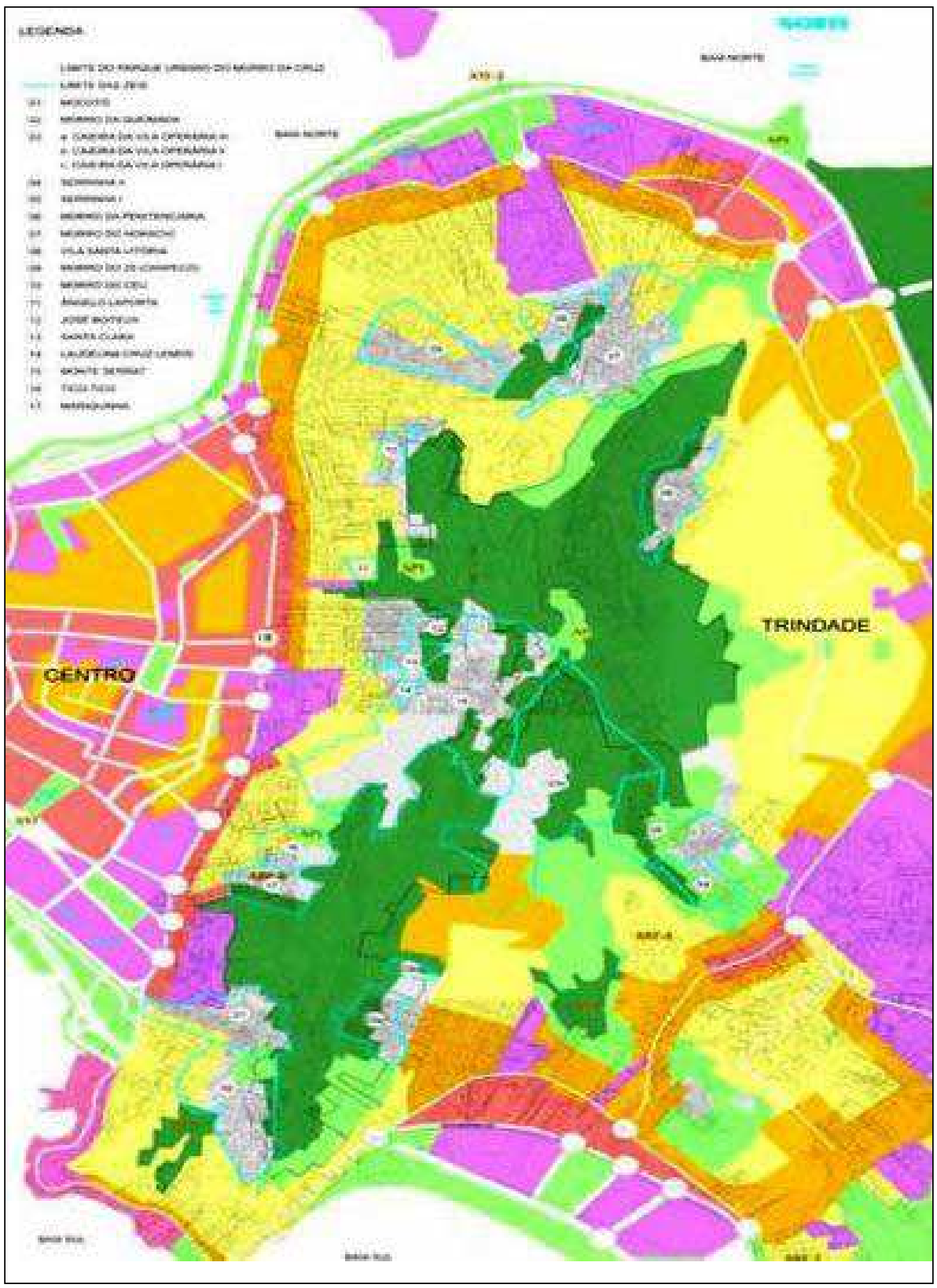

Fonte: PMF/SMHSA (2008b) 
Assim, em dezembro de 2005, após processo de elaboração com as comunidades, ocorreu a aprovação e sanção por parte da Câmara dos Vereadores e da Prefeitura da LC N ${ }^{\circ}$ 207/2005, que alterou o Plano Diretor do Distrito Sede no MMC, incluindo nas Áreas Especiais as Zonas de Especial Interesse Social (ZEIS) desta região. A partir desse momento o poder público municipal construiu um novo desenho metodológico (Figura 2): cada comunidade dialoga em particular com a prefeitura e todas têm assento (através das representações via associação de moradores) no núcleo gestor do PAC-Florianópolis para o MMC, onde além de cada comunidade e a prefeitura, - representada pelas seguintes secretarias: Habitação e Saneamento Ambiental; Assistência Social; e Obras - têm assento também a Floram, a Comcap, a Casan e a Celesc.

\section{O projeto}

As ações em 2006, no âmbito da prefeitura, consistiram na busca de recursos para a execução das obras de infraestrutura propostas. Também foram fechados os traçados dos polígonos das áreas de ZEIS nas comunidades e foram executados os levantamentos das áreas de risco através do Plano Municipal de Redução de Riscos em Escorregamentos (UFSC, 2007).

Em 2007, com o lançamento do PAC pelo Governo Federal, o projeto proposto pela PMF para o MMC foi reformulado, sendo realizadas algumas ações com vistas à qualificação do mesmo, por exemplo, discussões com as lideranças comunitárias e equipe técnica, audiências públicas, etc. As obras foram aprovadas (não só as de infraestrutura) neste mesmo ano e, em março de 2008, com a vinda do Presidente Luiz Inácio Lula da Silva a Florianópolis, ocorreu o lançamento oficial do programa e a liberação da verba num total de 54,6 milhões. Do montante total, 25 milhões da União, 15,6 milhões do governo do Estado e 14,6 milhões, contrapartida da prefeitura, como demonstra o Gráfico 1.

Segundo a Secretaria de Habitação da PMF, os objetivos gerais do projeto eram os seguintes: melhoria das condições de vida, inclusão social (saúde, educação, habitação e assistência social) e implantação de infraestrutura. Dos investimentos previstos, tiveram enfoque maior aqueles destinados basicamente às obras de infraestrutura e urbanização (água e esgoto, rede elétrica, transporte vertical, habitação). A área de abrangência do projeto é de $2.151 .000 \mathrm{~m}^{2}$, sendo que, deste total, $656.964 \mathrm{~m}^{2}$ correspondem à área ocupada, e $1.494 .036 \mathrm{~m}^{2}$ à área do parque. 
Gráfico 1. Orçamento geral do PAC/MMC/Florianópolis

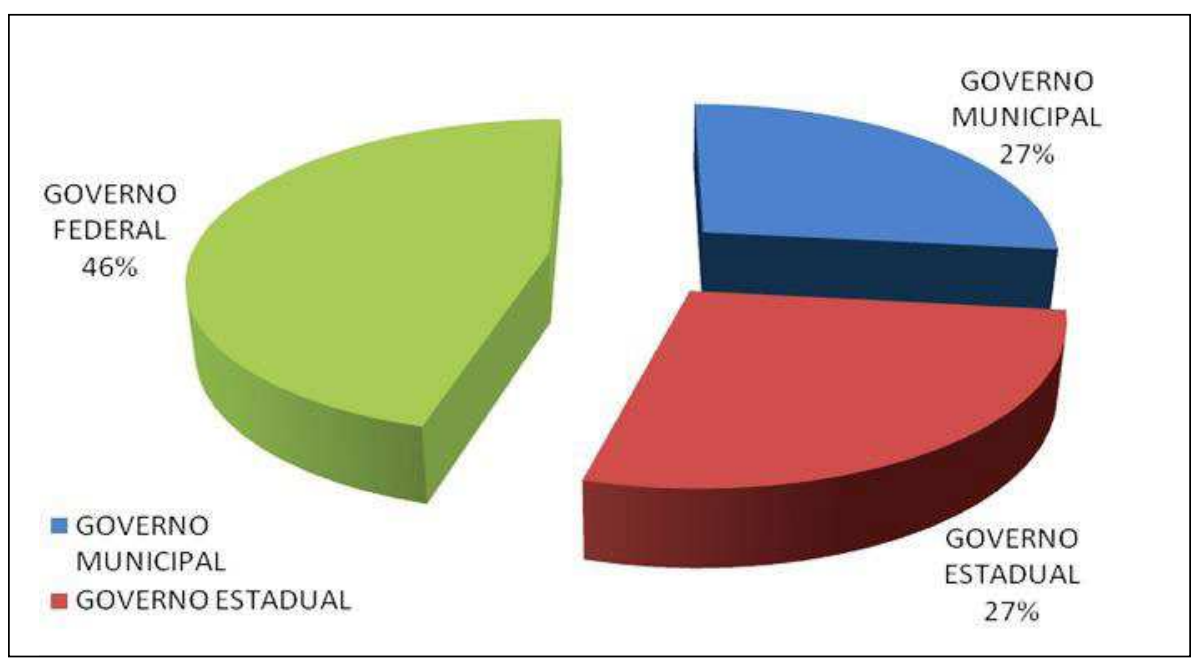

Fonte: Adaptado da PMF/SMHSA de Florianópolis, 2008a.

Com relação às obras, os números previstos foram os seguintes: instalação de 26 mil metros de rede de esgoto; 24 mil metros de rede de abastecimento de água; ampliação de 11 mil metros da rede de energia elétrica; 55 mil metros quadrados de pavimentação nova; 800 mil metros quadrados de recuperação

Figura 3. Abertura de via

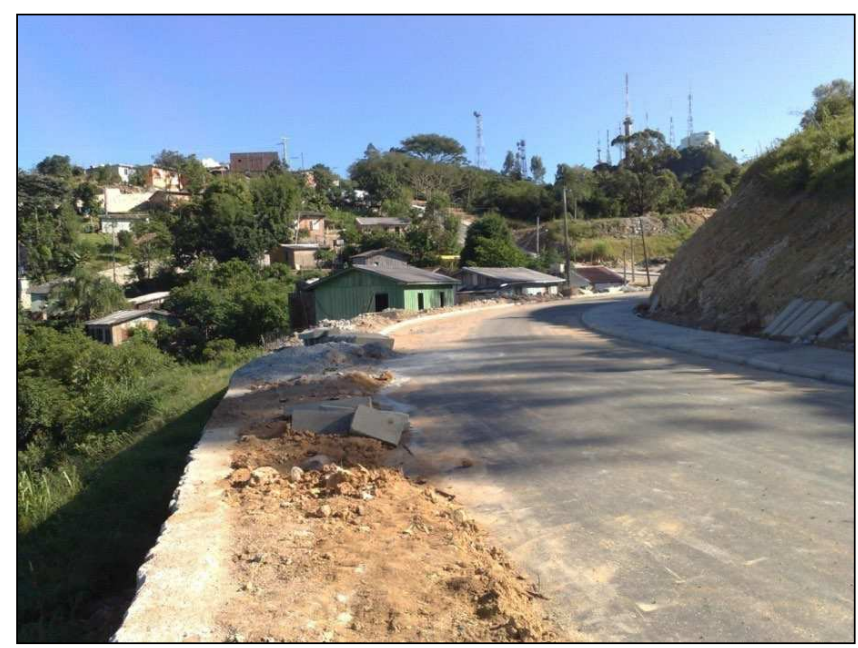

A Trans-Caieira possibilitou a ligação rodoviária entre as Comunidades do Mont-Serrat e Alto da Caieira, e hoje serve também de ligação alternativa entre a Trindade e o Centro da Capital. Fonte: Tomás (acervo pessoal) 2009. 
de pavimentos; remoção e reassentamento de 438 habitações (PMF, SMHSA, 2008a). O projeto antevia ainda a instalação do transporte por cremalheiras ou bondinhos nas comunidades do Morro do Céu, Rua José Boiteux e na Rua Treze de Maio, no Mocotó, o que até 2014 não foi sequer projetado em detalhes.

Na Tabela 1 pode-se observar a distribuição dos investimentos previstos, nas seguintes ações: terraplenagem; pavimentação (Figura 3); drenagem pluvial; abastecimento de água; sistema coletor de esgoto; rede de distribuição de energia elétrica; contenção de encostas; transporte vertical; habitação, módulo hidráulico e módulo de caixa d'água, implantação do parque do maciço, recuperação ambiental de áreas degradadas, coleta de resíduos sólidos, regularização fundiária e trabalho social (PMF, SMHSA, 2008).

Tabela 1. Investimentos do PAC/MMC/Florianópolis

\begin{tabular}{l|r}
\multicolumn{1}{c|}{ Ações Previstas } & \multicolumn{1}{c}{ R\$ } \\
\hline Projetos & $571.135,78$ \\
\hline Terraplenagem & $430.208,09$ \\
\hline Pavimentação & $4.172 .527,01$ \\
\hline Drenagem pluvial & $2.525 .170,79$ \\
\hline Rede de água e esgoto & $12.043 .579,14$ \\
\hline Rede elétrica & $2.988 .184,66$ \\
\hline Contenção (muros) & $5.122 .245,34$ \\
\hline Habitações, módulos sanitários e terrenos & $19.546 .288,21$ \\
\hline Transporte vertical & $2.300 .000,00$ \\
\hline Parque do maciço & $1.250 .000,00$ \\
\hline Supervisão obras & $625.000,00$ \\
\hline Trabalho social & $1.616 .676,22$ \\
\hline Resíduos sólidos - lixo & $131.378,20$ \\
\hline Regularização. Fundiária & $1.135 .400,00$ \\
\hline Equipamentos comunitários & $233.371,22$ \\
\hline Total & $54.691 .164,66$
\end{tabular}




\section{Áreas de risco}

As remoções de residências situadas em áreas ambientalmente frágeis ainda não foram quantificadas, mas envolvem situações como a bacia suspensa encontrada em levantamento realizado pela empresa Iguatemi no Plano de Manejo do Parque Urbano do MMC, e também casas que se encontram muito próximas a córregos e em outras situações onde a precariedade habitacional põe em risco a família.

A metodologia utilizada para a identificação das habitações das áreas de risco alto e risco muito alto teve como base o Plano Municipal de Redução de Riscos, fotos aéreas (480 analógicas e150 digitais) e visitas dos técnicos no campo ${ }^{1}$. O Plano Municipal de Redução de Risco (PMRR) por escorregamentos é um documento que contempla "uma série de diretrizes técnicas e gerenciais que permite ao poder público a implementação de ações estruturais e não-estruturais em assentamentos precários no município" (PMF/ SMHSA, 2007, p.5).

Tabela 2. Número de habitações sujeitas a remoções, por Comunidade, em áreas de risco alto e muito alto

\begin{tabular}{l|c}
\multicolumn{1}{c|}{ Assentamento } & $\begin{array}{l}\text { Habitações sujeitas à remoção- } \\
\text { áreas de risco alto e muito alto }\end{array}$ \\
\hline Caieira & 111 \\
\hline Mont Serrat & 30 \\
\hline Morro da Mariquinha & 21 \\
\hline Morro da Penitenciária & 60 \\
\hline Morro da Queimada & 15 \\
\hline Morro do 25 & 12 \\
\hline Morro do Céu & 3 \\
\hline Morro do Horácio & 21 \\
\hline Santa Clara/José Boiteux & 13 \\
\hline Serrinha & 12 \\
\hline Monsenhor Topp & 0 \\
\hline Vila Santa Vitória & 11 \\
\hline Total & $\mathbf{3 0 9}$ \\
\hline
\end{tabular}

Fonte: Excerto de relatório cedido pela SMHSA de Florianópolis, 2007.

${ }^{1} \mathrm{O}$ grau de risco foi estabelecido utilizando critérios definidos na metodologia elaborada pelo Ministério das Cidades e desenvolvida pelo CEPED/UFSC - Centro Universitário de Estudos e Pesquisas Sobre Desastres. 
Segundo este mesmo relatório, o índice geral de remoções previstas, que envolve as 18 comunidades, ficou em torno de $19 \%$ para as áreas de risco alto e muito alto ${ }^{2}$, como visto na Tabela 2.

Quase todas as remoções previstas, identificadas no projeto de infraestrutura, dizem respeito às obras do sistema viário e foram pensadas principalmente visando à melhoria da circulação interna. A partir do traçado destas novas vias mapearam-se:

[...] as casas que necessitam ser removidas, tanto para alargamentos de ruas como para implantação de vias novas de ligação. Praticamente em todas as comunidades existe algum tipo de intervenção com remoção de unidades habitacionais. As remoções serão ou indenizadas ou assentadas na própria comunidade. (PMF/ SMHSA, 2007, p. 9)

No entendimento da Prefeitura, em suma, buscava-se com estas ações a inclusão das 5,6 mil famílias que vivem no MMC, sobretudo através de ações de melhoria das condições de habitação, da instalação de infraestrutura e da recuperação ambiental.

\section{Considerações finais}

A identificação de uma sucessão de territorialidades no Maciço do Morro da Cruz, demonstra um incessante processo de reterritorialização - por vezes com longos períodos de duração, por vezes em breves períodos - desse espaço que novamente adquire novas características: as obras do PAC-Florianópolis, através das novas vias de circulação e outras obras de infraestrutura, evidenciam esse processo.

No entanto, serão as ações do PAC adequadas para promover a inclusão desta população empobrecida e diminuir a segregação socioespacial? E ainda, qual o significado destas obras? O que será que irá acontecer com as comunidades, a inclusão social e urbana realmente se realizará?

Com base nos relatos e entrevistas, é possível avançar em mais algumas questões sobre o futuro deste território: com o acesso facilitado pela abertura da via Transcaieira, com a abertura ao público do Parque Natural do Maciço do Morro da Cruz, e com tantas outras obras de infraestrutura, aos poucos a cidade se dá conta das modificações ocorridas, integrando ao seu cotidiano as mudanças sobrevindas dos 54 milhões de reais investidos nesta porção da

\footnotetext{
${ }^{2}$ A elaboração do Plano Municipal de Redução de Riscos (de escorregamentos) - PMRR - para o município de Florianópolis foi conduzida conforme contrato 0261/SMHSA/2006 celebrado entre a Universidade Federal de Santa Catarina - UFSC e a Prefeitura Municipal de Florianópolis - PMF, no período de maio a dezembro de 2006.
} 
cidade. Enquanto isso, a tão esperada regularização fundiária não progride, mantendo a precariedade da posse pela maioria dos moradores. Se alcançada a regularização, esta manterá os moldes e limites da Lei das ZEIS, garantindo a continuidade das ocupações, ou então teremos uma nova reterritorialização, desta vez controlada pelo elitizado mercado imobiliário de Florianópolis, com a consequente expulsão dos moradores atuais das diversas comunidades?

Na elaboração do Plano Diretor retomado pelo atual prefeito de Florianópolis, (2012 - 2016), vemos nova alteração nas obras destinadas ao MMC pelo programa do PAC. Segundo o prefeito, a construção do teleférico do MMC, prevista para iniciar em 2014, estaria no rol das obras que viriam a colaborar para o Plano Diretor Participativo (PDP), ligando o Centro à Trindade, reforçando a conexão já realizada pela via Transcaieira. No entanto, a nova proposta elaborada pelo Instituto de Planejamento Urbano de Florianópolis (IPUF) agrega um enfoque turístico antes inexistente. Estende o teleférico a regiões centrais da cidade, como as proximidades da Praça XV, incorporando novos usuários ao equipamento - turistas e pessoas interessadas em chegar à Trindade rapidamente. Do ponto de vista da inclusão social e urbana, como já mencionado anteriormente, este pode ser um aspecto positivo, mas mais uma vez a pergunta que não quer calar é se este mesmo aspecto não seria uma ampla porta de entrada para o capital imobiliário.

\section{Referências}

BRASIL. Estatuto da Cidade - Guia para Implementação pelos Municípios e Cidadãos: Lei n. 10.257, de 10 de julho de 2001, que estabelece diretrizes gerais da política urbana. Brasília Câmara dos Deputados, Coordenação de Publicações, 2001. 272 p.

CÂMARA MUNICIPAL DE FLORIANÓPOLIS. Lei Municipal $N^{o}$ 6893/2005 de 08 de dezembro de 2005. Cria o Parque Urbano do Morro da Cruz e dá outras providências. Florianópolis, 08/12/2005. Disponível em: www.cmf.sc.gov.br . Acesso em: 20 jun. 2013.

Lei Complementar $N^{\circ} 207 / 2005$, de 20 de dezembro de 2005. Altera em caráter emergencial o Plano Diretor do Distrito Sede no Maciço do Morro da Cruz e dá outras Providências. Florianópolis, 20/12/2005. Disponível em: www.cmf.sc.gov.br. Acesso em: 20 jun. 2013.

HAESBAERT, Rogério. O Mito da Desterritorialização: do Fim dos Territorios à Multiterritorialidade. 3. ed. Rio de Janeiro: Bertrand Brasil, 2007. 400p.

MARICATO, Ermínia. As ideias fora do lugar e o lugar fora das ideias. In: ARANTES, Otília; VAINER, Carlos B.; MARICATO, Ermínia. A cidade do Pensamento Único: Desmanchando consensos. Petrópolis, RJ: Vozes, 2000. p. 121-192.

PEREIRA, Elson M. Demandas Populares no Planejamento das Cidades: redefinição do papel das cidades, Democratização e Governança Urbana. In: REUNIÃO ANUAL DA SBPC, 58, 2006, Florianópolis. Anais... Florianópolis, SC, 2006. 
PREFEITURA MUNICIPAL DE FLORIANOPOLIS / SMHSA (Secretaria Municipal de Habitação e Saneamento Ambiental) Relatório Interno, Florianópolis, 2006a. (mimeo)

(Secretaria Municipal de Habitação e Saneamento Ambiental). Programa de Fiscalização e Controle de Ocupações (Contrato ${ }^{\circ}$ 511/ SMHSA/2005). Etapa 2/ Relatório $n^{\circ} 2$. Levantamento e Análise das Informações Documentais, Fontes de Consultas, Temáticas e Estatísticas. IGPlan, Florianópolis, 2006b. Disponível em: http://portal.pmf.sc.gov.br/arquivos/arquivos/ pdf/17_06_2010_18.34.44.d682d569b847ea1cf21b7a45079324bd.pdf Acesso em: 09 de jun. 2015 .

(Secretaria Municipal de Habitação e Saneamento Ambiental). Excerto de Relatório Interno do Projeto do Programa de Aceleração do Crescimento (PAC), 2007. (mimeo)

(Secretaria Municipal de Habitação e Saneamento Ambiental). Projetos e Ações no Maciço do Morro da Cruz - . Florianópolis, Março 2008. Acesso em 06 de jun., 2009 http://www. pmf.sc.gov.br/habitacao/habitacao/dados conjuntos/morro da_cruz/apresentacao mmc comunidades.pdf. (não mais disponível).

(Secretaria Municipal de Habitação e Saneamento Ambiental). Projetos e Ações no Maciço do Morro da Cruz. Florianópolis, 2008a. (Apresentação: para as comunidades, 22 slides)

(Secretaria Municipal de Habitação de Habitação e Saneamento Ambiental). Projeto do Maciço do Morro da Cruz. Florianópolis, 2008b. Disponível em: http://www.pmf.sc.gov.br/ entidades/habitacao/index.php? $\mathrm{cms}=$ projeto + macico + do + morro + da + cruz\&menu $=9$ Acesso em: 09 de jun. 2015.

RAFFESTIN, Claude. Por uma Geografia do Poder. São Paulo: Khedyr, 2011. 242 p.

ROLNIK, Raquel; NAKANO, Kazuo. As armadilhas do Pacote Habitacional. Le Monde diplomatique Brasil. São Paulo: v. 2, n. 20, mar., 2009, p.4-5. Disponível em: http://www.diplomatique.org.br/artigo.php?id=461 Acesso em: 09 de jun. de 2015.

SCHEIBE, Luiz Fernando. Aspectos geológicos e geomorfológicos. In: PEREIRA, N. do V. (Org.) A Ilha de Santa Catarina: espaço, tempo e gente. Florianópolis: Instituto Histórico e Geográfico de Santa Catarina, 2002. p. 43-60.

SCHEIBE, Luiz Fernando et al. A Parceria Universidade e Comunidade na Implantação das ZEIS e Parque Municipal no Maciço do Morro da Cruz, Area Central de Florianópolis, SC. In: SEMINÁRIO NACIONAL sobre o tratamento de áreas de preservação permanente em meio urbano e restrições ambientais ao parcelamento do solo. 2007, São Paulo, Anais, v. 1, São Paulo: FAUSP, 2007. (CD-ROOM).

SOUZA, Marcelo L. O Desafio Metropolitano: Um Estudo sobre a Problemática Sócio-espacial nas Metrópoles Brasileiras. Rio de Janeiro: Bertrand Brasil, 2005. 366p.

THÉRY, H .; MELLO, N.A. de. Atlas do Brasil Disparidades e Dinâmicas do Território. São Paulo: EDUSP, v. 1., 2005. 312 p.

TOMÁS, Elaine D. Antigos e Novos Olhares sobre o Maciço do Morro da Cruz: de Não Território a Território do PAC-Florianópolis. Florianópolis, 2012. 361f. Tese (Doutorado em Geografia), Centro de Filosofia e Ciências Humanas, Programa de Pós-graduação em Geografia, Universidade Federal de Santa Catarina, Florianópolis, 2012. 
UNIVERSIDADE FEDERAL DE SANTA CATARINA - UFSC (Centro Universitário de Estudos e Pesquisas Sobre Desastres - Ceped, Departamento De Engenharia Civil/Ecv. ) Plano Municipal de Redução de Riscos - PMRR. / Relatório Final. Florianópolis, 2006/2007. Disponível em: http://www.pmf.sc.gov.br/arquivos/arquivos/pdf/29 $05 \quad 2013 \quad 14.07 .04 .83 a 43 e-$ 3801c20344afe06b645226b7b3.pdf Acesso em: 09 de jun.2015.

Submissão em: 09/02/2015

Revisão em: 15/04/2015

Aceite em: 08/05/2015

Elaine Dorighello Tomás é arquiteta e urbanista pela PUC/Campinas. Mestre (1996) e Doutora (2012) em Geografia pela UFSC. Atuou como docente na área de Planejamento Urbano e Regional nos cursos de Arquitetura na PUC-Campinas, em1989; e na Unochapecó, em 2013). Tem experiência nos seguintes temas: urbanização de favelas; desenvolvimento urbano; áreas de risco; implementação de Planos de ZEIS (Zonas Especiais de Interesse Social) e avaliação das obras do PAC. Endereço para correspondência: Rodovia João Paulo, 1030, bloco C, apt. 201. Florianópolis, Santa Catarina - CEP 88030-300 E-mail: elainetomas@gmail.com

Luiz Fernando Scheibe é geólogo, doutor em Ciências (Mineralogia e Petrologia) pelo Instituto de Geociências da Universidade de São Paulo (1986). Atualmente é pesquisador 2 do CNPq e professor titular emérito voluntário da UFSC. Atua na área de Geociências e nos Programas de Pós-Graduação em Geografia e Interdisciplinar em Ciências Humanas da UFSC, com ênfase em Geoecologia e Hidrogeologia. Coordena o projeto Rede Guarani/Serra Geral: www.rgsg.org.br. E-mail scheibe2@gmail.com 